This is the peer reviewed version of the following article: Pike, I. H. and Tocher, D. R. (2016), Could an El Niño event put dietary supplies of n-3 long-chain polyunsaturated fatty acids (EPA and DHA) in jeopardy. Eur. J. Lipid Sci. Technol., 118: 1684-1691, which has been published in final form at http://doi.org/10.1002/ejlt.201400647. This article may be used for noncommercial purposes in accordance With Wiley Terms and Conditions for self-archiving. 
Review Article

\title{
Could an El Niño event put dietary supplies of n-3 long-chain polyunsaturated fatty acids (EPA and DHA) in jeopardy
}

\author{
Ian H. Pike*, ${ }^{1}$, Douglas R. Tocher ${ }^{2}$ \\ ${ }^{1}$ Chard, Bovingdon Green, SL7 2JL, UK \\ ${ }^{2}$ Institute of Aquaculture, School of Natural Sciences, University of Stirling, Stirling FK9 4LA, \\ UK \\ *Correspondence: $\quad$ Ian H. Pike, Marlow, UK \\ E-mail: $\quad$ ianhpike@aol.com
}

Running Title: Effect of an El Niño event on dietary supplies of EPA and DHA

Keywords: Fish oil / EPA + DHA / Salmon / Human health / El Niño.
Abbreviations: CVD, cardiovascular disease; DHA, docosahexaenoic acid (22:6n-3); DPA, docosapentaenoic acid (22:5n-3); EPA, eicosapentaenoic acid (20:5n-3); LC-PUFA, long-chain polyunsaturated fatty acids. 


\begin{abstract}
The beneficial effects of n-3 long-chain polyunsaturated fatty acids, especially EPA and DHA, for human health are widely recognised. Intakes of these fatty acids in many parts of Europe fall far short of the recommended intake, especially in young people. The most robust evidence from human health studies demonstrating beneficial effects is that for cardiovascular disease. Other beneficial effects have been reported for inflammatory diseases such as rheumatoid arthritis, Crohn's disease and ulcerative colitis, cognitive and visual development in preterm infants, and on various psychological/behavioural and psychiatric disorders. For European consumers fish is the main source of EPA and DHA, especially oily fish, and in particular farmed Atlantic salmon. With evidence of a strong El Niño type event occurring in the Pacific currently (2015/16), fish stock biomasses have drastically declined and permitted fishing heavily reduced. Subsequent fish oil shortages have resulted in increased substitution of fish oil with vegetable oil in feeds for farmed salmon. A significant fall in EPA and DHA in these fish and a reduction in intake by consumers are expected in the short term. Avoiding fish oil shortages causing reductions in EPA and DHA intake by consumers in the future may be possible through the production of DHA-rich algal biomass if the cost can be reduced. Genetically modified crops which might also be a source of these fatty acids are unlikely to be acceptable for salmon feeds in Europe in the near future.
\end{abstract}

\title{
Practical applications
}

If farmed Atlantic salmon is to continue to be an important source of EPA and DHA in European diets, especially those in the UK, consideration will have to be given to obtaining new sources of these fatty acids. It would be prudent to follow the development of cheaper forms of DHA-rich algal biomass for incorporation into salmon feeds. Any relaxation of the public's objections to the use of genetically modified crops to produce ingredients for salmon feeds should be followed. It may present the opportunity to use, for example, genetically modified Camelina sativa as an alternative source. 


\section{Introduction}

The beneficial effects of n-3 long-chain polyunsaturated fatty acids (LC-PUFA), especially eicosapentaenoic acid (EPA; 20:5n-3) and docosahexaenoic acid (DHA; 22:6n-3), on human health are widely recognised. There are over 2000 published reports, including epidemiological and randomised controlled trials, which generally show positive benefits (summarised briefly below). Furthermore, fish and fish oil have long been appreciated as almost unique sources of n-3 LC-PUFA to the human population [1,2]. The present paper presents an assessment of the implications that this has on the supply of these important nutrients, and discusses factors potentially influencing and limiting supply including the effects of an El Niño event (El Niño Southern Oscillation -ENSO).

\section{Importance of n-3 LC-PUFA in human health}

Evidence of the beneficial effects of dietary EPA and DHA on human health has been largely based on epidemiological studies and randomised controlled (intervention) trials, although laboratory studies investigating biochemical and molecular mechanisms have also provided mechanistic support to these in vivo approaches [3]. Many recommendations for EPA and DHA intakes have been produced by a large number of global and national health agencies and associations, and government bodies [4]. In their review of the recommended amounts of EPA plus DHA, Givens and Gibb [1] showed an average value of 450 mg per day.

Despite the very wide ranging studies on health effects of n-3 LC-PUFA, the most robust evidence demonstrating beneficial effects of dietary EPA and DHA remains that for cardiac and cardiovascular disease (CVD). Epidemiological studies, looking at n-3 LC-PUFA intake (fish/fish oil) and/or status (blood/tissue fatty acid compositions) consistently show protective effects, reducing the risk of developing CVD [5]. Randomised controlled trials, normally designed for patients with some disease already (i.e. in at-risk patients), have also been generally positive and show that patients benefit from dietary n-3 LC-PUFA therapy [6,7]. Until recently, metaanalyses were also largely positive [8,9] although there have been some recent studies questioning the efficacy of n-3 PUFA supplements [10,11]. The biochemical mechanisms underlying the beneficial effects of n-3 LC-PUFA are primarily based on their lowering of known risk factors for CVD and effects on platelet function [12]. Based on their effects on CVD, many health agencies worldwide recommend up to $500 \mathrm{mg} / \mathrm{d}$ of EPA and DHA for reducing CVD risk or $1 \mathrm{~g} / \mathrm{d}$ for secondary prevention in existing CVD patients, with a dietary strategy for achieving $500 \mathrm{mg} / \mathrm{d}$ being to consume 2 fish meals/week with at least one of oily fish [13-16]. 
There is evidence for beneficial effects of n-3 LC-PUFA in many other conditions and pathologies although it tends to be less robust than that for CVD. With inflammatory diseases the best evidence is for rheumatoid arthritis [17], although doses of n-3 LC-PUFA required to gain benefit are around $3 \mathrm{~g}$ per day, and there is also increasing evidence in Inflammatory Bowel Disease such as Crohn's disease and ulcerative colitis [18]. It should be noted that vascular diseases often have an inflammatory beginning. Supporting human studies, there is a very large body of research into the mechanisms of action of n-3 LC-PUFA on inflammatory pathways [19-22]. Regarding neurological function, there is robust evidence that DHA supplements have positive beneficial outcomes on cognitive and visual development in pre-term infants [23]. There have also been several reports of potential beneficial effects of dietary DHA supplementation in various psychological/behavioural/psychiatric disorders including attention deficit hyperactivity disorder and it is becoming recognized that n-3 LC-PUFA may help to prevent/mitigate various pathological conditions associated with the normal aging process including dementia/Alzheimer's disease [24,25]. There is limited epidemiological evidence indicating that consumption of oily fish or taking n-3 LC-PUFA supplements may have a protective effect (i.e. decreasing risk) in colorectal, breast and prostate cancers [26]. However, further evidence is difficult to obtain as randomised, controlled trials similar to those carried out in CVD are not possible in cancer, but there are studies indicating some beneficial effects of n-3 LC-PUFA supplementation in chemotherapy [27].

Although the overwhelming weight of evidence supports beneficial effects of dietary n-3 LC-PUFA there has been some negative reporting such as that on prostate cancer $[28,29]$ that impacted on sales of fish oil capsules for direct human consumption [30]. However, a very recent meta-analysis across approximately 20 studies did not support an association between n-3 LC-PUFA and prostate cancer [31]. Other meta-analyses studies have questioned the efficacy of n-3 supplements for the secondary prevention of cardiovascular disease [11,32,33]. However, these meta-analyses studies have been hotly debated and disputed particularly over the influence of one or two null studies that can skew the data [34]. In addition, recent work has suggested that, with concentrated n-3 ethyl ester supplements, the method of delivery has an impact and that these should be taken with a fatty meal in order to stimulate a full digestive response and ensure proper digestion and maximum bioavailability of the EPA and DHA [35].

\section{Sources of n-3 LC-PUFA and intake recommendations.}

Studies of intakes of the n-3 LC-PUFA, in particular EPA and DHA, in parts of the European population show a wide range from under $100 \mathrm{mg}$ per day in females 18 to 39 years of age and children in Belgium, to $590 \mathrm{mg}$ per day for adults in Northern Europe [1]. Taking the UK as an example, adult intake was $244 \mathrm{mg}$ per day, with $199 \mathrm{mg}$ per day from fish, $37 \mathrm{mg}$ from meat and $9 \mathrm{mg}$ from eggs. Ruminant animals grazing grass (dairy cows, beef and sheep) can convert a small 
proportion of the $\alpha$-linolenic acid (18:3n-3) they consume to EPA and DHA $[36,37]$. Grass has only a low lipid content, but this has a high proportion of $\alpha$ linolenic acid. Unsaturated lipids are extensively bio-hydrogenated in the rumen, but small (trace) amounts of $\alpha$-linolenic acid are believed to be converted to EPA and DHA. Grass fed beef and dairy cows have been found to have traces of EPA and DHA in the meat and milk respectively. The contribution of land-animal meat consumed by humans to EPA and DHA intake was primarily due to $16 \mathrm{mg}$ from poultry [38] compared with $27 \mathrm{mg}$ estimated by [1]. There is evidence of limited production of these fatty acids in poultry from $\alpha$-linolenic acid, which is present in grasses, see above, and some vegetable oils including rapeseed oil [39]. They showed that a variety of sources of $\alpha$-linolenic acid included in the diet resulted in both EPA and DHA being present in intramuscular lipids of broiler meat. Most poultry reared in Europe have very little fishmeal (which contains fish lipids) in their feed nowadays and only from one to 10 days of age, so that the deposition of n-3 LC-PUFA from this source would be minimal. So the conversion from $\alpha$ linolenic acid in full-fat rapeseed meal [39] which many poultry receive may, to a limited extent, offset the reduction of EPA and DHA from fish products in poultry (broiler) feeds which has occurred in the past five years.

The consumption of poultry meat in the UK has risen to around 469 g/person/week, according to the National Diet and Nutrition Survey, 2014 [40]. The only recent study of the fat composition of poultry obtained from retailers is that from [38]. Based on cooked chickens obtained from supermarkets that study showed a content of EPA plus DHA of approximately $23 \mathrm{mg}$ and $26 \mathrm{mg} / 100 \mathrm{~g}$ respectively in skinless breast and leg meat. Taking $24 \mathrm{mg} / 100 \mathrm{~g}$ as a representative content of EPA plus DHA, this equates to $16 \mathrm{mg} / \mathrm{person} /$ day from poultry meat consumed.

Of concern is that the intake of EPA and DHA from fish, poultry and other landanimal products is inadequate. Surveys show that young people eat less fish than older people and so are more dependent on land animal products as a source of these fatty acids.

Although there has been an increase in the production of refined and deodorised fish oil going into nutraceuticals - such as fish oil capsules and foodstuffs supplemented with n-3 LC-PUFA, the majority of young people are not believed to consume significant quantities, if any [1]. Clearly there is a need to increase intake and fish products are the most effective way. Of these, salmon is the most important as the largest contributor of these fatty acids in the diet of many Europeans (especially in Ireland, Belgium and the UK). Although the average intake of n-3 LC-PUFA from seafood in Europe was $350 \mathrm{mg}$ per day in 2010 [41] many individuals would get far less, particularly in those countries with low per capita intake of seafood. According to [42], the main oily fish species consumed on an annual basis were salmon $1.72 \mathrm{~kg}$, herring $1.18 \mathrm{~kg}$, mackerel $0.87 \mathrm{~kg}$ and sardine $0.71 \mathrm{~kg}$. Salmon, and particularly farmed salmon, which accounts for $98 \%$ 
of total salmon, only $2 \%$ being wild [42], was the major oily fish species consumed. However, for many European countries outside Scandinavia and the Mediterranean areas, little oily fish is consumed except salmon. Clearly there is a need to increase fish intake, but efforts to do so have not been very successful in young people (18-24 years old)(1). So for many consumers on low intakes of fish where the majority is salmon they are very dependent on the contribution of that fish. With the prospects of an El Niño reducing supplies of fish oil how might this affect the intakes of n-3 LC-PUFA from farmed salmon?

\section{Could an El Niño event be developing?}

The US National Oceanographic and Atmospheric Administration (NOAA) uses the Oceanic Niño Index (ONI) as the standard for identifying El Niño (warm) events in the tropical Pacific (Niño 3.4 region). Events are defined as five consecutive overlapping three-month periods at or above the +0.5 anomaly for warm events. They are further classified as weak ( 0.5 to $0.9 \mathrm{C}$ surface temperature (SST) anomaly), moderate (1.02 to 1.4 ), strong (1.5 to 1.9$)$ and very strong (over 2.0) [43].

According to a recent report from NOAA the current El Niño has just been classified as strong, and possibly very strong, with the expectation that it might be one of the largest to have occurred since 1950 [44].

In the areas of the Pacific most affected by the rising sea temperatures, the fishing grounds are normally some of the richest in the world. The Peruvian organisation IMARPE (Insituto del Mar del Peru), which undertakes exploratory fishing to assess fish stock biomass, suspends fishing during periods of El Niño to allow stocks to recover. The consequence of this is that production of both of fishmeal and fish oil is dramatically reduced at that time. This is reflected in fish oil production in Peru and Chile which between them produce around half the global production. The effect on the latter is shown in Figure 1. The global fish oil production figures were kindly supplied by the publication Oil World [45]. The arrows indicate El Niño years and strength. In the years of the very strong El Niño global fish oil production appeared to drop by over $15 \%$. In 2015, production had already fallen to just over 800 thousand tonnes, about $15 \%$ down reflecting the current El Niño.

During the period of El Niño when fishing is allowed, it becomes more difficult as, to try to avoid the warm water, forage fish such as anchovy and horse mackerel move close to shore or into deeper water [46]. The food supplies for the fish is reduced and, as a result, they become emaciated with higher mortality. As well as the dramatic reduction in fish catches the oil yield from the fish is reduced as a consequence. 


\section{The consequences of an EI Niño for the fish oil available for aquaculture}

Because fish oil use in nutraceuticals commands a higher price than other outlets, usage is unlikely to be reduced for that purpose and, therefore, virtually all of the fall in production of fish oil will be reflected in that which is available for aquaculture, and in particular salmon feeds. These feeds contain high levels of lipid - up to $40 \%$ in grower feeds. It has been shown that the lipid composition of the diet is reflected in that of the fish, especially oily fish such as salmon and trout (salmonids) $[47,48]$. So any further reduction in the use of fish oil could lead to a reduction in n-3 LC-PUFA levels in the flesh of farmed salmon.

\section{Changes in the n-3 LC-PUFA content of the flesh of salmonids.}

A recent publication reported lipid contents and fatty acid compositions of salmon products obtained from major UK retailers in March 2013 [49]. Based on the data in [49] the average contents of lipid and its n-3 and n-6 PUFA compositions (expressed as \% total fatty acids) in the salmon products have been calculated (Table 1). Some of the farmed salmon products had relatively high contents of 18:1n-9, 18-2n-6 and 18:3n-3, characteristic of vegetable oils and these products also had lower percentages of EPA and DHA. In contrast, farmed salmon with high levels of 16:0 and 22:1 characteristic of fish oil had higher proportions of EPA and DHA. There was a clear correlation between the levels of fatty acid markers of vegetable oil and fish oil reflecting contents in feeds and the final proportions of n-3 LC-PUFA in the flesh.

This confirmed earlier research where fish oil was replaced progressively with linseed oil that is rich in $\alpha$-linolenic acid [50]. The authors pointed out that this fatty acid is a favoured substrate for $\beta$-oxidation in salmonids and mammals. It is not regarded as detrimental in diets for humans. In many human diets in Northern Europe the n-6:n-3 PUFA ratio is unbalanced and heavily in favour of n-6 PUFA (typically $15: 1$ or higher) [51]. The dietary ratio of $n-6: n-3$ PUFA is not directly associated with cardiovascular disease risk according to the OTILIP study [52], which showed it was the absolute amounts of dietary linoleic and $\alpha$-linolenic acids that were of greatest relevance to the conversion of the latter to EPA and DHA. Although linseed oil is not generally used in salmonid feeds, the vegetable oil predominantly used, rapeseed oil, also contains $\alpha$-linolenic acid. Levels of this fatty acid are not as high in rapeseed oil compared to linseed oil, and it also contains significant amounts of n-6 PUFA as reflected in the composition of the farmed salmon flesh. Nevertheless it will still provide sufficient $\alpha$-linolenic acid at a reasonable n-6:n-3 PUFA ratio ( 2:1) to allow production of the n-3 LC-PUFA, EPA and DHA. Due to this endogenous production, the total substitution of marine ingredients in the feed gives some production of EPA and DHA in salmon flesh [53]. Further evidence of the reduction in flesh content of EPA and DHA with reduced dietary levels has been found [54]. 


\section{Effect of reducing fish oil in salmon feeds from 12.5 to $5.0 \mathrm{~g} / 100 \mathrm{~g}$ on the content of n-3 LC-PUFA in flesh.}

The largest producer of farmed salmon in Europe is Norway which also supplies the greatest amount into the European market. According to NOFIMA, the fish oil content of salmon feeds in Norway had fallen to $11 \%$ in 2013 [55]. Recent price increases are likely to reduce this to below $10 \%$. To illustrate the consequences the effect of a reduction in fish oil content from $12.5 \%$ to $5 \%$, the resultant EPA plus DHA content of flesh has been calculated (Table 2). Based on the regressions given by [47] the relationship between the EPA and DHA in the diet and in the flesh was linear; the relationship gave correlation coefficients of $0.966(\mathrm{p}=$ $0.0001)$ and $0.979(\mathrm{p}=0.0013)$, respectively. Assuming that the total lipid content of the diet was $30 \mathrm{~g} / 100 \mathrm{~g}$, of which $23 \mathrm{~g} / 100 \mathrm{~g}$ was fatty acids, the fish oil reduction in the diet would have reduced the EPA plus DHA in salmon flesh from 2.5 to $1.3 \mathrm{~g} / 100 \mathrm{~g}$ (Table 2 ).

Taking the UK as an example of a population with low fish consumption, the average per capita daily intake of EPA plus DHA is $232 \mathrm{mg}$ (see [1] and also section 3). Of this, $131 \mathrm{mg}$ is from oily fish. Salmon provides around $2.5 \mathrm{~g} / 100 \mathrm{~g}$ flesh based on feeds as used in 2013 (Table 2). The effect of reducing the dietary content of fish oil from $12.5 \%$ to $5 \%$ would reduce these fatty acids in salmon flesh from $2.5 \mathrm{~g}$ to $1.3 \mathrm{~g} / 100 \mathrm{~g}$.

For a meal size of $140 \mathrm{~g}$ (one meal per week) the reduction becomes $3.5 \mathrm{~g}$ to $1.8 \mathrm{~g}$, that is $50 \mathrm{mg}$ to $26 \mathrm{mg}$ per day. The average intake of $232 \mathrm{mg}$ per day would as a consequence be reduced to $208 \mathrm{mg}$. As the average intake of $232 \mathrm{mg}$ is already below the intake recommended for maintaining health $(450 \mathrm{mg}$ ) (see above) the reduction of per capita intake due to lower fish oil inclusion in diets for farmed salmon to $208 \mathrm{mg}$ /day could in due course further compromise health. As El Niño events occur frequently (see Figure 1), they could jeopardise supplies of EPA plus DHA, and per capita intake, unless alternatives to fish oil as a source of n-3 LCPUFA become available..

\section{Possible future sources of EPA and DHA for salmon feeds}

Progress is being made identifying the heritability and mechanisms of n-3 LCPUFA deposition in salmon flesh [56]. Selective breeding rather than gene manipulation of fish may be the more appropriate way of enabling these findings to be applied. Progress is also being made in achieving high-level accumulation of EPA and DHA in transgenic oilseed crops [57]. Already the plant used, Camelina sativa, has been cultivated on a field scale and it is currently undergoing feeding trials in salmon [58]. Although current consumer attitudes in Europe would act as a barrier to the use of feed ingredients derived from transgenic plants, it is likely that these crops will be will be grown outside Europe, and the n-3 LC-PUFA-rich oils 
available for global aquaculture industries. This could pose a significant and serious challenge to European aquaculture until consumer attitudes towards genetic modification change.

Algal products rich in oil have been produced for some time on a small scale, making them very expensive. In the future it may be possible using heterotrophic fermentation technology to scale-up production and bring down costs to a level that will make algal biomass suitable as an additional source of DHA (and possibly EPA) to fish oil. A DHA-rich algal biomass (AB) produced from Schizochytrium $s p$. has been tested in two recently published trials with Atlantic salmon postssmolts. In one trial the $\mathrm{AB}$ was added at $2.5 \%$ or $5.2 \%$ of the diet to replace herring oil and maintain EPA plus DHA content, increasing the proportion of DHA relative to EPA [59]. The AB used contained a $61 \%$ fat, $29 \%$ DHA but only 0.3 $\%$ EPA in the oil. Diets were formulated with $48 \mathrm{~g}$ EPA plus DHA per kg oil. Growth of the fish, feed conversion and lipid content were similar and not affected by treatment. The EPA plus DHA contents of flesh were also not greatly affected by the treatment. It was found that the retention of these fatty acids from $A B$ was improved albeit largely due to the replacement of more easily oxidised EPA by DHA that is less easily oxidised, as was fish quality (gaping).

In a further trial with $\mathrm{AB}$ rich in DHA (composition not given) either $11 \%$ or $5.5 \%$ of this replaced $27 \%$ fish oil in the diet [60]. The fish oil was either sourced from the Northern or Southern hemispheres. That from the latter had a higher EPA: DHA ratio. Levels of these fatty acids were reduced with the $A B$ containing diets, especially with the lower level. The AB treatments resulted in poorer growth and feed conversion. Although lipid content of the flesh was similar, the EPA and DHA content was significantly reduced by the AB treatments. In these treatments the sum of these fatty acids in dietary lipid was less than half that in the fish oil treatments. Nevertheless, flesh levels were not reduced proportionately; they were reduced by about $35 \%$. This might reflect more efficient uptake from $A B$ as in the former trial [59]. However, when dietary levels of the fatty acids are reduced markedly the efficiency of uptake tends to increase possibly explaining part of the improved efficiency noted in [60]. 9 Conclusions

There have been wide ranging studies of the health effects of n-3 LC-PUFA in humans. There is robust evidence demonstrating beneficial effects of dietary EPA and DHA for cardiac and cardiovascular disease. There is evidence, though less robust, for beneficial health effects in many other conditions, including inflammatory diseases such as rheumatoid arthritis, and intestinal conditions such as Crohn's disease. Neurological functions, and cognitive functions in children, have been shown to improve with DHA supplementation of the diet.

A number of government bodies and national health agencies have recommended an intake of EPA plus DHA averaging $450 \mathrm{mg} /$ person/day. Yet intake in much of Europe is much less than this; for example, it is estimated in the UK that intake averages $232 \mathrm{mg} /$ person/day - see section 7 and [1]. 
It is now confirmed that the current El Niño in the Pacific has been classed as strong, and may be very strong. Global production of fish oil is already declining as a result of the detrimental effects of warmer than normal sea temperatures on stocks of forage fish off the South American coast. The reduction in supplies of fish oil globally, and price increases as a consequence, are expected to more than half its contribution of EPA and DHA in salmon feeds, salmon being a significant source of these fatty acids in the UK diet, for example. A reduction averaging 24 mg EPA plus DHA/person/day as a consequence is estimated which would cause an average intake drop from $232 \mathrm{mg}$ to $208 \mathrm{mg} /$ person/day against the recommended daily amount of $450 \mathrm{mg}$, further exacerbating the shortfall.

With aquaculture continuing to grow and fish oil supplies not increasing, and with dramatic drops in production each time an El Niño occurs, supplies of EPA and DHA for feeds will be put in jeopardy; new sources are urgently needed.

Technology to produce DHA-rich algal biomass from heterotrophic algae has been developed using fermentation technology. If this process can be scaled up to reduce the price of production, it could provide the additional supply of DHA, and to a lesser extent EPA, that fish farming and especially salmon production urgently need. Although the technology for the production of EPA plus DHA from plants such as Camelina sativa is now relatively well advanced, the need to use genetic modification is likely to rule out such a crop from European aquaculture in the near future.

\section{Acknowledgements}

The authors are grateful to Dr. Andrew Jackson and IFFO - The Marine Ingredients Organisation for providing information in connection with El Niño events.

The authors have declared no conflict of interest.

\section{References}

[1] Givens, D.I., Gibbs, R.A., Current intakes of EPA and DHA in European populations and the potential of animal-derived foods to increase them. Proc. Nutr. Soc. 2008, 67, 273-280.

[2] Tur J. A., Bibiloni M. M., Sureda A., Pons, A.. Dietary sources of omega-3 fatty acids: public health risks and benefits. Br. J. Nutr. 2012, 107, S23-S52.

[3] Gil, A., Serra-Majem, L., Calder, P.C., Uauy, R., Systematic reviews of the role of omega-3 fatty acids in the prevention and treatment of disease. $B r . J$. Nutr. 2012, 107, S1-S2.

[4] GOED., Global recommendations for EPA and DHA intake (Rev 16 April 2014). http://www.goedomega3.com/healthcare. Accessed 27 October 2014. 
[5] Delgado-Lista, J., Perez-Martinez, P., Lopez-Miranda, J., Perez-Jimenez, F., Long chain omega-3 fatty acids and cardiovascular disease: a systematic review. Br. J. Nutr. 2012, 107, S201-S213.

[6] Calder, P.C., Yaqoob, P., Marine omega-3 fatty acids and coronary heart disease. Curr. Opin. Cardiol. 2012, 27, 412-419.

[7] Delgado-Lista, J., Perez-Martinez, P., Lopez-Miranda, J., Perez-Jimenez, F., Long-chain omega-3 fatty acids and cardiovascular disease: a systematic review. Br. J. Nutr. 2012, 107, S201-S213.

[8] Casula, M., Soranna, D., Catapano, A.L., Corrao G., Long-term effect of high dose omega-3 fatty acid supplementation for secondary prevention of cardiovascular outcomes: A meta-analysis of randomized, double blind, placebo controlled trials. Atherosclerosis Suppl. 2013, 14, 243-251.

[9] Calder, P.C., Very long chain omega-3 (n-3) fatty acids and human health. Eur. J. Lipid Sci. Technol. 2014, 116, 1280-1300.

[10] Rizos, E.C., Ntzani, E.E., Bika, E., Kostapanos, M.S., Elisaf, M.S., Association between omega-3 fatty acid supplementation and risk of major cardiovascular disease events: A systematic review and meta-analysis. J. Am. Med. Assoc. 2012, 308, 1024-1033.

[11] Chowdhury, R., Warnakula, S., Kunutsor, S., Crowe, F., Ward, H.A., Johnson, L., Franco, O.H., Butterworth, A.S., Forouhi, N.G., Thompson, S.G., Khaw, K.-T., Mozaffarian, D., Danesh, J., Di Angelantonio, E., Associaton of dietary, circulating, and supplement fatty acids with coronary risk: A systematic review and meta-analysis. Ann. Intern. Med. 2014, 160, 398-406.

[12] Uauy, R., Valenzuela, A., Marine oils: The health benefits of n-3 fatty acids. Nutrition 2000, 16, $680-684$.

[13] ISSFAL, International Society for the Study of Fatty Acids and Lipids. Report of the Sub-Committee on Recommendations for intake of polyunsaturated fatty acids in healthy adults. ISSFAL, 2004, Brighton.

[14] Gebauer, S.K., Psota, T.L., Harris, W.S., Kris-Etherton, P.M., 2006. n-3 fatty acid dietary recommendations and food sources to achieve essentiality and cardiovascular benefits. Am. J. Clin. Nutr. 2006, 83, 1526S-1535S. 
[15] Aranceta, J., Pérez-Rodrigo, C., 2012. Recommended dietary reference intakes, nutritional goals and dietary guidelines for fat and fatty acids: a systematic review. Br. J. Nutr. 107, S8-22.

[16] European Food Safety Authority (EFSA) Panel on Dietetic Products, Nutrition and Allergies (NDA)., Scientific opinion related to the tolerable upper intake level of eicosapentaenoic acid (EPA), docosahexaenoic acid (DHA) and docosapentaenoic acid (DPA). EFSA J. 2012, 10, 2815.

[17] Miles, E.A., Calder, P.C., Influence of marine n-3 polyunsaturated fatty acids on immune function and a systematic review of their effects on clinical outcomes in rheumatoid arthritis. Br. J. Nutr. 2012, 107, S171-S184.

[18] Cabré, E., Mañosa, M., Gassulla, M.A., Omega-3 fatty acids and inflammatory bowel diseases - a systematic review. Br. J. Nutr. 2012, 107, S240-S252.

[19] Chapkin R.S., Kim, W., Lupton, J.R., McMurray, D.N., Dietary docosahexaenoic and eicosapentaenoic acid: Emerging mediators of inflammation. Prostaglandins Leukotrienes Essent. Fatty Acids 2009, 81, $187-191$.

[20] Serhan, C.N., Petasis, N.A., Resolvins and protectins in inflammation resolution. Chem. Rev. 2011, 111, 5922-43.

[21] Rangel-Huerta, O.D., Aguilera, C.M., Mesa, M.D., Angel Gil, A., Omega-3 long-chain polyunsaturated fatty acids supplementation on inflammatory biomarkers: a systematic review of randomised clinical trials. Br. J. Nutr. 2012, 107, S159-S170.

[22] Calder, P.C., n-3 Fatty acids, inflammation and immunity: new mechanisms to explain old actions. Proc. Nutr. Soc. 2013, 72, 326-336.

[23] Carlson, S.E., Werkman, S.H., Rhodes, P.G., Tolley, E.A., Visual acuity development in healthy preterm infants: effect of marine-oil supplementation. Am. J. Clin. Nutr. 1993, 58, $35-42$.

[24] Dangour, A.D., Andreeva, V.A., Sydenham, E., Uauy, R., Omega 3 fatty acids and cognitive health in older people. Br. J. Nutr. 2012, 107, S152-S158.

[25] Úbeda, N., Achóna, M., Varela-Moreirasa, G., Omega 3 fatty acids in the elderly. Br. J. Nutr. 2012, 107, S137-S151. 
[26] Gerber, M., Omega-3 fatty acids and cancers: a systematic update review of epidemiological studies. Br. J. Nutr. 2012, 107, S228-239.

[27] Bougnoux, P., Hajjaji, N., Ferrasson, M.N., Giraudeau, B., Couet, C., Le Floch, O., Improving outcome of chemotherapy of metastatic breast cancer by docosahexaenoic acid: a phase II trial. Br. J. Cancer 2009, 101, 1978 - 1985.

[28] Brasky, T.M., Darke, A.K., Song, X., Tangen, C.M., Goodman, P.J., Thompson, I.M., Meyskens Jr, F.L., Goodman, G.E., Minasian, L.M., Parnes, H.L., Klein, E.A., Kristal, A.R., Plasma phospholipid fatty acids and prostate cancer risk in the SELECT trial. J. Natl. Cancer Inst. 2013, 105, 1132-1141.

[29] Brasky, T.M., Till, C., White, E., Neuhouser, M.L., Song, X., Goodman, P., Thompson, I.M., King, I.B., Albanes, D., Kristal, A.R., Serum phospholipid fatty acids and prostate cancer risk: results from the prostate cancer prevention trial. Am. J. Epidemiol. 2011, 173,1429-1439.

[30] IFFO, The Marine Ingredients Organisation: Fishmeal and Fish Oil Statistical Yearbook 2014. In IFFO [online]. 2012 www.iffo.net.

[31] Alexander, D.D., Bassett, J.K., Weed, D.L., Barrett, E.C., Watson, H., Harris, W., Meta-analysis of long-chain omega-3 polyunsaturated fatty acids (LC $\omega$ 3PUFA) and prostate cancer. Nutr. Cancer 2015, 67, 543-554.

[32] Rizos, E.C., Ntzani, E.E., Bika, E., Kostapanos, M.S., Elisaf, M.S., Association Between omega-3 fatty acid supplementation and risk of major cardiovascular disease events: A systematic review and meta-analysis. $J . A m$. Med. Assoc. 2012, 308, 1024-1033.

[33] Wen, Y.T., Dai, J.H., Gao, Q., Effects of omega-3 fatty acid on major cardiovascular events and mortality in patients with coronary heart disease: A meta-analysis of randomized controlled trials. Nutr. Metab. Cardiovasc. Dis. 2014, 24, 470-475.

[34] GOED., GOED (Global Organization for EPA and DHA) Disputes JAMA Omega-3 Meta-Analysis. www.prweb.com/pdfdownload/9892902.pdf (posted 12 September 2012; accessed 27 October 2014)

[35] Davidson, M.H., Johnson, J., Rooney, M.W., Kyle, M.L., Kling, D.F., A novel omega-3 free fatty acid formulation has dramatically improved bioavailability during a low-fat diet compared with omega-3-acid ethyl esters: The ECLIPSE (Epanova ${ }^{\circledR}$ compared to Lovaza ${ }^{\circledR}$ in a pharmacokinetic singledose evaluation) study. J. Clin. Lipidology 2012, 6, 573-584. 
[36]Wood, J.D., Enser, M., Fisher, A.V., Nute, G.R., Richardson, R., Sheard, P.R., Improving reproduction for future needs: manipulating meat quality and composition. Proc. Nutr. Soc.1999, 58, 363-370.

[37] Petit,H.V., Dewhurst,R.J., Scollan,N.D., Proulx,J.G., Kahlid,M., Haresign,W., Twagiramungu,H., Mann,G.E. Milk production and composition, ovarian function and prostaglandin secretion of dairy cows fed omega-3 fats. J. Dairy Sci. 2002. 85. 889-899

[38] Dalziel,C.J., Kliem,K.E., Givens,D.I. Fat and fatty acid composition of cooked meat from UK retail chickens labelled as from organic and nonorganic production systems. Food Chemistry. 2015, 179, $103-108$.

[39] Azcona,J.O., Schang, M.J., Garcia,P.T., Gallinger,C., Ayerza Jr.R., Coates,W. Omega-3 enriched broiler meat: The influence of dietary $\alpha$-linolenic- $\omega-3$ fatty acids sources on growth, performance and meat fatty acid composition. Canadian Journal of Animal Science. 2008. 88. 257.

[40]Bates, B., Lennox, A., Prentice, A., Bates, C., Page, P., Nicholson, S., \& Swan, G. National Diet and Nutrition Survey, Results from Years 1-4 (combined) of the rolling Programme (2008/2009-2011/12). A survey carried out on behalf of Public Health England and the Food Standards Agency. 2014

[41] Micha, R., Khatibzadeh, S., Shi, P., Andrews, K.G., Engell, R.E., Powles, J., Ezati, M., Mozaffarian, D., Global, regional and national consumption levels of dietary fats and oils in 1990 and 2010: split analysis including 266 country specific nutritional surveys. Table 3. Characteristics of adult global consumption of key dietary fats and oils in 2010. BMJ., 2014, 348: G2272.

[42] European Market Observatory for Fisheries and Aquaculture Products-The EU Fish Market, 2014, 10.

[43] Null,J. El Niño and La Niña years and intensities. NOAA, www.ggweather.com/enso.htm 2015

[44] Climate Prediction Centre (NOAA), National Centres For Environmental. Protection. Alert System Status: El Niño Watch.

www.cpc.ncep.noaa.gov/products/analysis_monitoring/lanina/enso_evol ution-status-fcsts-web.pdf(Nov.2015)

[45] ISTA Mielke GmbH. Oil World. Hamburg. www.oilworld.de

[46] Shepherd,C.J., Monroig,O., Tocher, D.R. Production of high quality, healthy salmon from a changing raw material base, with special reference to a 
sustainable Scottish industry. A study commissioned by the Scottish Aquaculture Research Forum (SARF). http/www.sarf.org.uk/cmsassets/documents/216181-554802.sarf sp007.pdf.

[47] Bell, J.G., McEvoy, J., Tocher, D.R., McGee, F., Campbell, P.J., Sargent, J.R., Replacement of fish oil with rapeseed oil in diets of Atlantic salmon (Salmo salar) affects tissue lipid composition and hepatocyte fatty acid metabolism. J. Nutr. 2002, 132, 1535-1543.

[48] DeSilva, S.S., Francis, D.S., Tacon, A.G.J., Fish oils in aquaculture: in retrospect. In: Fish oil replacement and alternative lipid sources in aquaculture feeds. Eds. G.M. Turchini, W.-K. Ng, D.R. Tocher. Taylor \& Francis, CRC Press, Boca Raton, 2010, pp. 1-20.

[49] Henriques, J., Dick, J.R., Tocher, D.R., Bell, J.G., Nutritional quality of salmon products available from major retailers in the UK: Content and composition of n-3 long-chain polyunsaturated fatty acids. Br. J. Nutr. 2014, 112, 964-975.

[50] Bell, J.G., Henderson, R.J., Tocher, D.R., Sargent, J.R., replacement of dietary fish oil with increasing levels of linseed oil: modification of/fatty acid compositions in Atlantic salmon (Salmo salar) using a fish oil finishing diet. Lipids 2004, 39, 223 - 234.

[51] Simopoulos, A.P. The importance of omega-6/omega-3 fatty acid ratio in cardiovascular disease and other chronic diseases. Experimental Biology and Medicine, 2008, 233, 674-688.

[52] Griffin, B.A. How relevant is the ratio of dietary n-6 to n-3 polyunsaturated fatty acids to cardiovascular disease risk? Evidence from the OPTILIP study. Curr. Opin. Lipidol., 2008,19, 57-62.

[53]Sanden, M., Stubhaug, I., Berntseen, M.H.G., Lie, O., Torstensen, B.E., Atlantic salmon (Salmo salar L.) as a net producer of long-chain marine $\omega-3$ fatty acids.J. Agric. Fd. Chem., 2011, 59, 12697-12706.

[54] Tocher, D.R., Francis, D.S., Coupland, K., n-3 Polyunsaturated fatty acidrich vegetable oils and blends. In: Fish Oil Replacement and Alternative Lipid Sources in Aquaculture Feeds. Eds. G.,M. Turchini, W.-K. Ng, D.R. Tocher. Taylor \& Francis, CRC Press, Boca Raton, 2011, pp. 209-244.

[55] Ytrestфyl, T., Aas, T.S., Ásgård, T. Utilisation of feed resources in production of Atlantic salmon in Norway. Aquaculture. 2015. 448, 365 - 374. 
[56] Leaver, M.J., Taggart, J.B., Villeneuve, L.A.N., Bron, J.E., Guy, D.R., Bishop, C.S., Houston, R.D., Matika, O., Tocher, D.R., Heritability and mechanisms of n-3 long-chain polyunsaturated fatty acid deposition in the flesh of Atlantic salmon. Comp. Biochem. Physiol. 2011, 6D, 62-69.

[57] Luis-Lopez, N., Haslam, R.P., Napier, J.A., Sayanova, O., Successful highlevel accumulation of fish oil omega-3 long-chain polyunsaturated fatty acids in a transgenic oilseed crop. Plant J. 2014, 77, $198-208$.

[58] Betancor, M.B., Sprague, M., Usher, S., Sayanova, O., Campbell, P.J., Napier, J.A., Tocher, D.R., A nutritionally-enhanced oil from transgenic Camelina sativa effectively replaced marine fish oil as a source of eicosapentaenoic acid for farmed Atlantic salmon (Salmo salar). Science Reports 2015, 5, 8194.

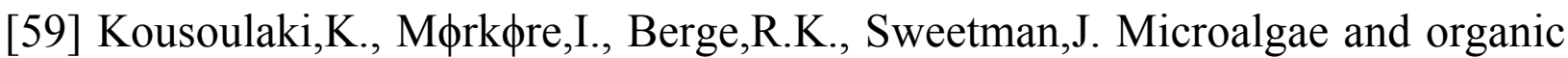
minerals enhance lipid retention efficiency and fillet quality in Atlantic salmon. Aquaculture 2016, 451, 47 - 57.

[60] Sprague,M., Walton,J., Campbell,P.J., Strachen,F., Dick,J.R., Bell,J.G. , replacement of fish oil with a DHA-rich algal meal derived from Schizochytrium Sp. On the fatty acid and persistent organic pollutant levels in diets and flesh of Atlantic salmon posts smolts. Food Chemistry, 2015, 185, $413-421$.

[61] Ackman, R.G., Fatty acid composition of fish oils. In: Nutritional Evaluation of Long-chain Fatty Acids in Fish Oil. Eds. S.M. Barlow, M.B. Standsby. Academic Press, London, 1982, 25 - 139. 
Figure 1

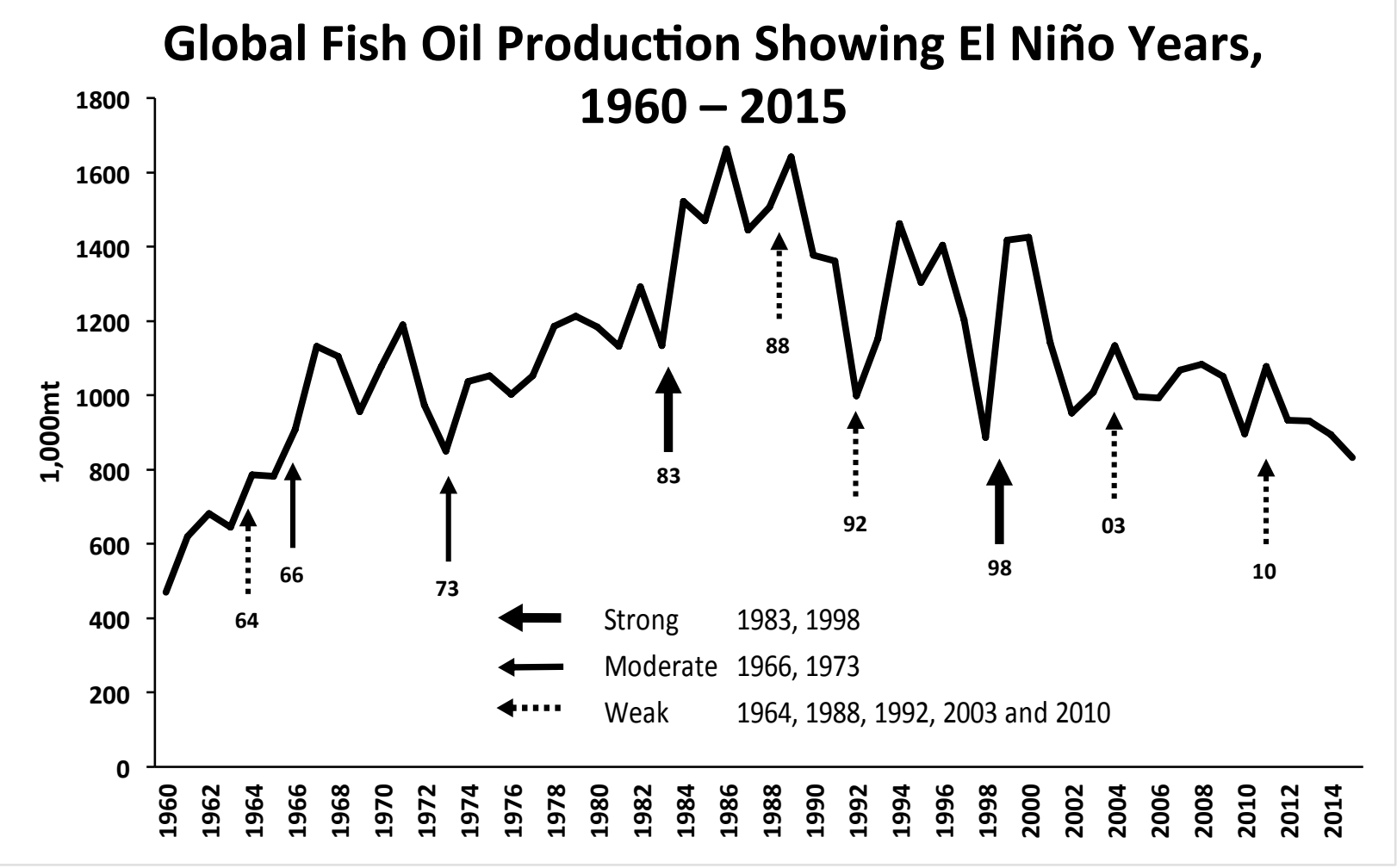


Table 1. The average lipid contents, n-3 PUFA and n-6 PUFA compositions, and proportions of EPA, docosapentaenoic acid (DPA) and DHA (expressed as g/100g total fatty acids) in salmon products sourced from UK retailers in spring 2013.

\begin{tabular}{lcc}
\hline & Mean & SD \\
\hline Total lipid (g/100g) & 11.7 & 3.4 \\
$\Sigma \mathrm{n}-3$ & 21.2 & 4.7 \\
$\Sigma \mathrm{n}-6$ & 11.6 & 3.9 \\
Ratio n-3:n-6 & 2.2 & 1.4 \\
$20: 5 \mathrm{n}-3$ (EPA) & 5.5 & 2.3 \\
$22: 5 \mathrm{n}-3$ (DPA) & 2.3 & 0.8 \\
$22: 6 \mathrm{n}-3$ (DHA) & 7.5 & 2.6 \\
\hline
\end{tabular}


Table 2. The effect of reducing fish oil content of salmon diets from 12.5 to $5.0 \mathrm{~g}$ oil $/ 100 \mathrm{~g}$ feed on the calculated concentration of $\mathrm{n}-3$ LC-PUFA in fish flesh ${ }^{1}$.

\begin{tabular}{|c|c|c|c|}
\hline Changes in fish oil in salmon diets & $\begin{array}{l}\text { FA in diet }{ }^{2} \\
(\mathrm{~g} / 100 \mathrm{~g} \\
\text { feed })\end{array}$ & $\begin{array}{l}\text { FA in diet } \\
\text { (g/100g } \\
\text { lipid) }\end{array}$ & $\begin{array}{l}\text { FA in } \\
\quad \text { flesh }^{1} \\
\text { (g/100g flesh) }\end{array}$ \\
\hline $\begin{array}{l}\text { Amount of EPA from } 12.5 \mathrm{~g} \\
\text { oil } / 100 \mathrm{~g} \text { feed }\end{array}$ & 2.28 & 6.61 & 1.2 \\
\hline $\begin{array}{l}\text { Amount of EPA from } 5.0 \mathrm{~g} \\
\text { oil } / 100 \mathrm{~g} \text { feed }\end{array}$ & 0.91 & 2.64 & 0.55 \\
\hline $\begin{array}{l}\text { Amount of DHA from } 12.5 \mathrm{~g} \\
\text { oil } / 100 \mathrm{~g} \text { feed }\end{array}$ & 0.96 & 2.78 & 1.3 \\
\hline $\begin{array}{l}\text { Amount of DHA from } 5.0 \mathrm{~g} \\
\text { oil } / 100 \mathrm{~g} \text { feed }\end{array}$ & 0.39 & 1.13 & 0.73 \\
\hline
\end{tabular}

${ }^{1}$ Using regression in Fig. 2 of [47]

${ }^{2}$ Assuming dietary fish oil to be Peruvian produced from anchovy, horse mackerel, sardine and pilchard: EPA content, $18.2 \mathrm{~g} / 100 \mathrm{~g}$ oil; DHA content, $7.7 \mathrm{~g} / 100 \mathrm{~g}$ oil [61]. Total fatty acids in diets with mixed vegetable and fish oils assumed to be $85 \%$; in salmon flesh $80 \%$ [53]. 